\title{
Millennials' attitude toward chatbots: an experimental study in a social relationship perspective
}

\author{
Roberta De Cicco \\ Department of Neuroscience, Imaging and Clinical Sciences, \\ University of Chieti-Pescara, Chieti, Italy and \\ CAST, Center for Advanced Studies and Technology, University of Chieti-Pescara, \\ Chieti, Italy \\ Susana C. Silva \\ Católica Porto Business School, Universidade Católica Portuguesa, Porto, \\ Portugal, and \\ Francesca Romana Alparone \\ Department of Neuroscience, Imaging and Clinical Sciences, \\ University of Chieti-Pescara, Chieti, Italy
}

\begin{abstract}
Purpose-Chatbots represent an innovative channel for retailers to meet young customers' needs anywhere and at any time. Being an emergent technology, however, it is important to investigate more thoroughly how users perceive it, and which are the variables that enhance a positive attitude towards this technology. On this premise, this study applies a social relationship perspective to the design of chatbots addressed to younger consumers. Design/methodology/approach - The study adopts a between-participants factorial design to investigate the effects of visual cues (avatar presence vs avatar absence) and interaction styles (social-oriented vs taskoriented) on social presence and how this, in turn, enhances millennials' perceived enjoyment, trust and, ultimately, attitude towards the chatbot. A survey experiment was employed to conduct the study on data collected from 193 Italian millennials.

Findings - The results show that applying a social-oriented interaction style increases users' perception of social presence, while an insignificant effect was found for avatar presence. The partial least square structural equation modeling (PLS-SEM) analysis further confirms the hypothesised model.

Originality/value - The adoption of new digital technologies such as chatbots is likely to have a far reaching effect on retailers, consumers, employees and society. For this reason, a broad understanding of the phenomenon is needed. To the best of our knowledge, this is the first study to provide results from an experimental design in which both interaction style (social- vs task-oriented) and avatar (presence vs absence) of a chatbot are manipulated to directly explore social presence and its effect on trust, perceived enjoyment and millennials' attitude towards a chatbot applied for retailing purposes.
\end{abstract}

Keywords Chatbot, Interaction style, Avatar, Social presence, Trust, Enjoyment, Attitude

Paper type Research paper

\section{Introduction}

Over the last few years, retailers have been providing customers with various digital touchpoints as part of their ongoing use of digital technologies in the shopping process (Hagberg et al., 2016). Many of them have adopted chatbots as a complementary online marketing communication strategy to better engage and interact with their customers

(C) Roberta De Cicco, Susana C. Silva and Francesca Romana Alparone. Published by Emerald Publishing Limited. This article is published under the Creative Commons Attribution (CC BY 4.0) licence. Anyone may reproduce, distribute, translate and create derivative works of this article (for both commercial and non-commercial purposes), subject to full attribution to the original publication and authors. The full terms of this licence may be seen at http://creativecommons.org/licences/by/4.0/legalcode

Received 27 December 2019

Revised 20 January 2020

22 March 2020

27 March 2020

21 May 2020

10 June 2020

Accepted 10 June 2020

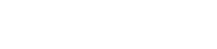


IJRDM 48,11

1214
(Gentsch, 2019). For example, chatbots used by the company 1-800- Flowers enable customers to order flowers, make payments and track delivery without leaving Facebook Messenger. Another example includes Northface, which launched its virtual shopping chatbased assistant to help customers to find the right jacket (Tuzovic and Paluch, 2018).

To clarify, chatbots are programs that simulate human conversation, allowing humans to interact with digital devices as if they were communicating with a real person (Oracle, 2019). Recent improvements in natural language processing, combined with the shift towards messaging as a primary channel for communication, have contributed to the enormous increase in popularity of chatbots in the retail industry (Gnewuch et al., 2018).

As mentioned by the news website Business Insider (2019), according to a report from research and markets, the chatbot market size is projected to grow from $\$ 2.6 \mathrm{bn}$ in 2019 to $\$ 9.4 \mathrm{bn}$ by 2024. Customer service, retail and e-commerce represent those market segments that are projected to grow their market size at the highest compound annual growth rate, owing to the increasing demand to provide customers with a seamless omnichannel experience (Business Insider, 2019). The ease and accessibility of building a chatbot (thanks to the numerous platforms and frameworks available for building them), the substantial developments in artificial intelligence $(\mathrm{AI})$ and the increased usage of messaging apps are the main factors pushing the chatbot industry forwards. Despite this, however, a lack of awareness about the outcomes of using chatbots within their various applications could constitute a threat to the growth of this market. Currently, the main challenge with chatbots involves interpretational problems: in most cases, chatbots cannot address more specific or complex requests, or do not always understand what the customer is asking (Brandtzaeg and Følstad, 2017). Thus, businesses which require only a relatively short number of options to fulfil online orders-i.e. those which can use an easier algorithm - are more likely to use chatbots (e.g. food delivery businesses). Due to the routinisation of activities and the limited recurrent tasks that allow for greater speed and lower costs (Leidner, 1993), online food delivery businesses are most likely to constitute a field in which the application of chatbots is easier to implement for companies and easier to use for customers.

This is particularly true for younger people, (e.g. millennials, the generation born between 1981 and 1996) as technology is significantly integrated into their daily lives (Moore, 2012). Being the first generation to experience the smartphone era, although millennials demand a customised service, they are not used to wait (Forbes, 2016). So, thanks to the real-time nature which allows consumers to get instant informal responses to their queries (Mero, 2018), and chats have become millennials' preferred option for obtaining customer support. In this perspective, chatbots are taking up the challenge of fulfilling this need, trying to assure a personalised service available to meet such young customers' needs anytime and anywhere in a way that - with traditional methods - was just not possible (Chung et al., 2018).

Chatbots are currently grabbing the attention of a growing number of researchers, addressing their interest in visual-conversational cues and interactivity of chatbots (Go and Sundar, 2019; Chattaraman et al., 2019) as well as their potential role in enhancing customers' satisfaction (Chung et al., 2018) and company perceptions (Araujo, 2018). According to these studies, the issue of creating a chatbot seems to be more of a conversational rather than a technical challenge. The question that arises is what is an appropriate format in terms of conversational traits for an effective implementation of chatbots for retailing?

As the conversational abilities of chatbots quickly improve, it is important to understand the emotional, relational and psychological outcomes that chatbots convey to the user through their communication (Ho et al, 2018). So, building on this premise, the current study aims to give insights into practitioners who wish to offer an engaging experience to young consumers through "conversations" with chatbots. Specifically, the present study aims to extend research on social features applied to chatbots (Chattaraman et al., 2019) by providing results from an experimental study in which both interaction style (social-oriented vs task-oriented) and visual cue (avatar presence vs avatar absence) were manipulated - through a fully functional chatbot 
set up for online food purchasing - in order to investigate how such features impact social presence, which in turn positively predicts trust, perceived enjoyment and, accordingly, millennials' overall attitude towards this technology. Thus, we expect to give a far-reaching understanding of the new forms of communication between retailers and consumers by focusing on a contemporary feature at the heart of the retail digital transformation.

\section{Literature review, theoretical framework and development of hypotheses}

The present study complements current research on chatbots applied for business purposes (Araujo, 2018; Chung et al., 2018), integrating and extending the earlier literature on humanchatbot interaction (Zarouali et al., 2018; Hill et al., 2015; Ciechanowski et al., 2019). In doing so, this study focuses on a social relationship perspective, based on the premise that chatbots are not merely a productive tool, but can also be seen as a more personal source of interaction that possesses and conveys social value (Brandtzaeg and Følstad, 2017).

A considerable body of research has focused on human-chatbot interactions. With respect to how users respond to the chatbot's enquiries, Hill et al. (2015) found that users communicate with chatbots using shorter messages and a less rich vocabulary compared to conversations with another human, while Corti and Gillespie (2016) found that people are less willing to repair misunderstandings with chatbots compared to humans. According to the authors, this is probably due to the lower expectations people have of chatbots, as they are believed to be unable to engage in complex intersubjective processes. Turning to the motivations that drive people to use chatbots, Brandtzaeg and Følstad (2017) showed that most people tend to engage in a chatbot conversation for productivity, entertainment and the social-relational benefits they provide. Other studies investigated how interacting with the chatbot affects business outcomes in terms of attitude towards the brand (Zarouali, 2018), love for the brand (Trivedi, 2019) or emotional connection with the company (Araujo, 2018). Although a number of studies have explored human-chatbot interactions, fewer of these studies have investigated how people rely on social cues such as language, interactivity and the capability of chatbots - applied for business purposes - to express emotions (Toader et al., 2020). From this perspective, Araujo (2018) was among the first to compare both the frame introducing the chatbot and the humanlike cues (human name and greetings vs computer-like language) in terms of perceived anthropomorphism, social presence and company perception. Go and Sundar (2019) argued that identity cues (message interactivity and human identity) represent key factors in developing certain expectations for interactivity that impact individuals' psychological, attitudinal and behavioural responses to chatbots. Chattaraman et al. (2019), whose research involved an older sample (61-89), found that users with low Internet competency prefer taskoriented interactions, while high competency users prefer a social-oriented interaction with respect to social outcomes (e.g. perceived interactivity and trust).

Within human-computer interaction (HCI), a critical aspect is represented by social presence, that is the sense of being with another (Gefen and Straub, 2003), where "the other" can be either a human or AI (Biocca et al., 2003). Communication and HCI researchers have typically been interested in social presence because it can mediate the effects of other variables of central concern such as attitudes towards the mediated others, features of the interface, persuasion, illusions of reality, learning and memory (Biocca et al., 2003). Since social presence positively affects attitudinal antecedents, researchers have drawn on the social presence theory to explore the lack of human warmth on the Internet (Hassanein and Head, 2005). Many of them have discussed the potential of website features to infuse the online interface with human warmth (Hassanein and Head, 2005, 2007), but research on what cues positively affect social presence in human-chatbot interaction is still poor (Araujo, 2018). To the best of our knowledge, no study has yet explored whether millennial consumers favour an online social presence in chatbots, and how determining this is for their shopping experience. Against this background, drawing from the social presence theory, where the
Millennials' attitude toward chatbots 
IJRDM 48,11

1216

perception of a person as "real" is determined by intimacy and immediacy, this study fills this research gap by understanding how to leverage such intimacy and immediacy through conversational design and visual cues, and further investigate whether and how social presence affects trust, perceived enjoyment and millennials' attitude towards this technology.

Following Gefen and Straub (2003) we believe a higher priority should be given for identifying conversational cues that enhance users' perception of social presence. As Araujo's manipulation of human-like cues (human name and greetings) turned out not to be a sufficient trigger for social presence, we believe Chattaraman et al.'s (2019) interaction style to be the more exhaustive approach to researching the effect of social conversational cues on social presence. Likewise, we consider cartoon avatars an interesting feature on which to conduct research, due to their appeal with companies and due to the fact that, to date, in the domain of chat-based platforms, only chatbots' highly realistic human-like avatars have been researched (e.g. Go and Sundar, 2019; Ciechanowski et al., 2019), contrary to what happened in the past for virtual assistants residing on a website page (Qiu and Benbasat, 2009).

In view of the lack of knowledge about millennials' preferences towards online social presence within chatbots, our aim is to understand how to enhance social presence in millennial-chatbot interaction and to know whether this creates a more trustful, enjoyable and favourable shopping process for this cohort.

\section{Interaction style and avatars as antecedents of social presence}

In the e-retail context, chatbots assume the role of advisors, typically associated with salespeople in physical settings (Qiu and Benbasat, 2009). Building social relationships between salespeople and customers increases the chance of positive word of mouth, customer satisfaction, loyalty and purchases, reflecting the fact that customers desire not only functional but also social benefits (Qiu and Benbasat, 2009). This advocates giving a higher consideration to a social relational approach in human-chatbot interaction, as such an experience can be significantly strengthened by both hedonic, social or relational motivations (Brandtzaeg and Følstad, 2017).

In online settings, users perceive agents as both interaction mediators and social actors, a process that is explained by the computers are social actors (CASA) paradigm which posits that people ascribe social attributes to a computer technology, especially when it is perceived to possess characteristics typically associated with human behaviour (Reeves and Nass, 1996). According to this theory, the more the agents transmit emotions and express empathy and sympathy, the more users positively evaluate them and develop social and emotional bonds with the agents (Komiak and Benbasat, 2006). In line with this, the same ought to apply to chatbots, since users should, in theory, prefer chatbots which express emotions, sympathy and empathy compared to chatbots that provide only neutral information about products (Liu and Sundar, 2018).

Research highlights how social cues conveyed through chatbots should better align with the mental orientation of high task competency users (e.g. millennials), who possess the competences to easily meet functional goals and who place value on the social value of the interaction (Chattaraman et al., 2019). Specifically, a social-oriented interaction style, which meets socio-emotional and relational goals through conversational cues that highlight empathy, personality and friendliness (Van Dolen et al., 2007) is more effective for high task competency users in terms of social outcomes, compared to a task-oriented interaction style in which the language is formal and involves only on task dialogue which achieves functional goals, fulfils responsibilities and satisfies concerns for a productive outcome (Chattaraman et al., 2019).

While the idea of the customer as simply a rational and cognitive being can be viewed as incomplete, research about the ability chatbots have in making people perceive emotions and how such emotions enhance a positive attitude is still limited (Smestad and Volden, 2018). In order to shed light on this topic, we investigate social presence, a construct that refers to the extent to which a medium is perceived as sociable, warm, sensitive and personal when it is used 
to interact with others (Gefen and Straub, 2003). The social features of human-chatbot interactions and the way in which users' perceptions of chatbots are swayed by social presence have gained attention only recently (Araujo, 2018; Go and Sundar, 2019). Previous research has focused on social presence to explore the lack of human warmth in the online environment (Chen et al., 2005). Studies in this field show that personalisation and recommendation positively influence perception of social presence (Gefen and Straub, 2003). Hassanein and Head (2005) proved how an increased sense of social presence on websites can be achieved by stimulating the perception of interaction with other humans (e.g. through socially rich text, pictures and video) or by providing means for actual interaction with others (e.g. personalised greetings).

In view of the specific nature of the chatbot, social conversational cues of online chat agents could facilitate a feeling of interacting with other people (Go and Sundar, 2019). Thus, we hypothesise that

H1. Users who interact with a chatbot set up using a social-oriented interaction style will perceive a greater level of social presence compared to those who interact with a chatbot set up with a task-oriented interaction style.

As higher levels of social presence can improve social exchanges and strengthen source cue effects (Skalski and Tamborini, 2007), technology developers are interested in identifying features that increase the potential for social presence. Besides conversational cues, in view of the chat-based environment where human-chatbot interactions take place, another important aspect worth understanding is the role of visual cues in providing human-like attributes to chatbots (Go and Sundar, 2019). According to Gefen and Straub (2003), personal photographs and pictures convey personal presence in the same manner as texts do. Specifically, avatars, which are a graphical embodiment or visual presentation, are growing in popularity in many interfaces used for computer-mediated communication (CMC) including social media and e-commerce (Nowak and Fox, 2018). Scholars agree that a crucial trait of avatars is their potential to situate or embed communication and generate an experience of co-presence in shared virtual environments (Nowak and Biocca, 2003). EtemadSajadi (2016) found that avatars increased the level of social presence and the emotional appeal of a company's website. Wang et al. (2007) argued that social cues inherent in avatars induce perceptions of website socialness, leading to increased pleasure and arousal.

More specifically, cartoon-like characters are particularly appreciated in HCI (humancomputer interaction) because they lower customer expectations towards the character's skills and help matching the technical abilities of the system (Luo et al., 2006). This is a factor which should not be overlooked, since the conversational skills of chatbots are still limited and conflict may occur between chatbots' ability and users' perceptions of that ability, thus generating frustration. Go and Sundar (2019) argued that in HCI, the more visually realistic the representation is the higher the expectations of the user are. Thus, we purposely investigate a feature which is increasingly applied by companies on Facebook Messenger to overcome this issue, but of which little is yet known. In fact, the majority of the studies on chatbots focus on human-realistic pictures rather than less anthropomorphic characters like avatars (Ciechanowski et al., 2019; Go and Sundar, 2019).

Therefore, we propose the following hypothesis:

H2. Users who interact with a chatbot which displays the avatar will perceive a greater level of social presence compared to those who interact with a chatbot that does not display the avatar.

\section{Social presence influence on perceived enjoyment and trust}

In traditional retail environments, salespeople's characteristics influence customers' emotions, such as enjoyment while shopping (Lee and Dubinsky, 2003). Similar to what
Millennials' attitude toward chatbots 
IJRDM 48,11

happens during the interaction with salespeople, perceived enjoyment is an important component of the social benefits customers acquire from communicating with an artificial agent that acts on behalf of the company. Previous research highlighted the relevance of social presence in the transmission of positive emotions within a medium (McKenna et al., 2002). Lombard and Ditton (1997) were among the first to suggest the effect that social presence has on media users in increasing involvement, persuasion and enjoyment. Perceived enjoyment is a significant experiential aspect of offline and online shopping, describing how an individual perceives something to be fun (Hassanein and Head, 2005). It is largely classified as an intrinsic motivation for adopting a technology (Davis et al., 1992). Over the years, studies have confirmed the key role that social presence plays in positively influencing perceived enjoyment (Cyr et al., 2007; Hassanein et al., 2009; Shen, 2012); Hassanein and Head (2005) proved that increased levels of social presence have a positive impact on enjoyment for websites selling apparel, while Shen (2012) provides support for the role that social presence plays in predicting enjoyment of social shopping websites. Studies of the electronic retail sector have so far explored the role of enjoyment in online shopping (Koufaris, 2002) and instant messaging (Li et al., 2005), but research investigating enjoyment in human-chatbot interaction is still at a very early stage. On this premise, we hypothesise the following:

H3. Higher levels of social presence will have a positive effect on perceived enjoyment.

Trust represents the willingness to accept being vulnerable to the actions of another party, based on the expectation that they will carry out a particular action important to the trustor (Mayer et al., 1995). Trust is at the heart of social and financial transactions, especially in the online retailing environment where this "social exchange variable" (Alnawas and Hemsley-Brown, 2018) plays a key role in the success or failure of online businesses ( $\mathrm{Lu}$ et al., 2016). Because chatbots are a digital form of salesperson and trust is particularly important for personal selling, it is important to understand how consumers form trust with chatbots (Whang and Im, 2018). Social presence is one factor that might enhance trust, by reducing the uncertainty and the vulnerability consumers feel towards merchants, especially in the online context (Jiang et al., 2019). In face-to-face human interactions, trustworthiness is usually manifested even within trivial (yet considered important) social cues (Qui and Benbasat, 2009). When it comes to human to non-human interaction, this process is no different, as consumers rely on a variety of sources to form their trusting beliefs, and perceived quality of the information provided by the agent is only one of the factors that contribute to the cognitive evaluation of the agent's trustworthiness (Qui and Benbasat, 2009). Generally, in an e-service and retailing context, social attributes conveyed through social presence are believed to be both an enabler and an antecedent of trust (Gefen and Straub, 2003). In human-chatbot interactions, when users interact with a chatbot for the first time, they have very few cues from which to judge the chatbot's trustworthiness. In this case, a socially rich experience should allow a chatbot to function as an information source that exhibits a human touch and higher credibility. On this premise we propose that

H4. Higher levels of social presence will have a positive effect on trust towards the chatbot.

\section{Perceived enjoyment and trust as antecedents of attitude towards the chatbot}

For those studies involving a fictitious online interaction with a chatbot that do not make it possible to obtain behavioural data, users' attitude is considered an appropriate dependent variable (Hassanein and Head, 2005). In fact, as Ajzen and Fishbein (1977) have argued, a person who holds a favourable attitude towards an action will be more inclined to perform a particular behaviour. Users' attitude was shown to be a valuable outcome variable in many contexts and studies on new technologies (Hassanein and Head, 2005). Because of that, research is interested in investigating what are the antecedents that may impact on this 
construct. The hedonic aspects concerning the online environment (e.g. online shopping) have been demonstrated to play a role that is at least equal to that of the instrumental aspects (e.g. usability) (Childers et al., 2001). Higher levels of intrinsic enjoyment and pleasure in computermediated environments are factors that produce a positive attitude (Kim et al., 2013). Hence, perceived enjoyment turns out to be a psychological consequence of social presence but also an antecedent to consumer attitude (Hassanein and Head, 2005). Many studies have examined the effect of perceived enjoyment on technology preferences, such as computers, websites and mobile. In the context of the online shopping experience, Lee et al. (2003) proved that shopping enjoyment was positively associated with online customer satisfaction (Suki and Suki, 2007). Other studies found perceived enjoyment to be positively related to attitude towards online shopping (Childers et al., 2001), television commerce (Yu et al., 2005) and website browsing (Van der Heijden, 2003). Based on the above-mentioned arguments we propose

H5. Higher levels of perceived enjoyment will have a positive effect on the attitude towards the chatbot.

In the online context, due to the unique characteristics of the virtual shopping environment (i.e. absence of face-to-face interactions or inability to directly see and touch a product), consumers feel greater uncertainty and heightened risk in their online buying decisions, especially when new channels are involved (Ha and Stoel, 2009). In case of new technologies or interactions with unknown companies and brands, research often refers to trust in terms of initial trust as a more appropriate interpretation of trust given the precocity of the interaction. In this regard, initial trust was found by Wu and Chen (2005) to influence attitude towards paying tax online. According to Siau and Shen (2003) both initial and continuous trust are affected by factors related to the vendor and the technology (interactivity, designed aesthetics and personalisation) and represent antecedents of attitude and intention to use the technology. Trust represents a central variable for online transactions where it reduces the uncertainty and vulnerability consumers feel when engaged in e-commerce, further allowing for the establishing of positive attitudes and retention of shoppers (Das, 2016). Being a prerequisite for a successful implementation of a new technology, the relationship between trust and attitude has been constantly studied by researchers (Wang and Benbasat, 2008; Ming-Chi, 2009). Prior empirical studies have incorporated and supported trust as an antecedent of attitude (Chen and Tan, 2004; Suh and Han, 2002). The impact of trust on attitude has been confirmed in many contexts and online retailing is no exception. Wu and Ke (2015) found trust to be a significant antecedent of attitude towards online shopping. Consumer trust in a company's website was shown to positively impact attitude towards the company and willingness to buy from the online vendor (Gefen and Straub, 2003). On this premise, we believe it is of major importance to assess the relationship between trust and attitude in human-chatbot interaction; therefore, we hypothesise that

H6. Higher levels of trust will have a positive effect on the attitude towards the chatbot. Figure 1 depicts the research model.

\section{Research method}

Design, participants and experimental procedure

Due to the routinisation of the tasks involved, online food delivery businesses are more likely to implement chatbots. Since in most cases chatbots still cannot address highly specific or complex requests (Brandtzaeg and Følstad, 2017), businesses in which a relatively short number of options are required to fulfil online orders - thus those which can use an easier algorithm - are more prone to the use of chatbots. The routinisation of activities and the limited recurrent tasks that provide greater speed and lower costs (Leidner, 1993) make online food delivery business a field in which the application of chatbots is easier to implement for
Millennials' attitude toward chatbots

1219 
IJRDM 48,11

1220

companies and easier to use for users. Despite this, however, a lack of awareness about the outcomes of using chatbots within this application can constitute a threat to the growth of this market. From this perspective, we adopted an experimental design to investigate how conversational cues and visual cues affect social presence and how this, in turn, affects attitude towards a chatbot applied for an online food delivery business.

Specifically, a between-participants factorial design 2 (interaction style: social-oriented or task-oriented) $\times 2$ (avatar: present or absent) was adopted. To implement the treatments, four different chatbots were created with Chatfuel. The interactions were carried out in Italian for an average of five minutes. Examples of the interaction with the chatbots (social-oriented vs task-oriented; avatar vs no avatar) are displayed in Appendixes 1-2. Appendix 3 provides the English translation of the human-chatbot interactions.

Participants were recruited using snowball sampling, where students enrolled in bachelor's and master's degree programmes in an Italian university participated in the study and helped researchers to recruit new subjects from among their acquaintances by sharing the link to the web-based survey with their peers on Facebook. Participants did not receive any compensation for participating in the study; they were free to choose whether to participate in the study and share it with their acquaintances. An essential requirement for participation was having a Facebook Messenger account (necessary in order to start the interaction with the chatbot). Participants were informed about the institution's ethical approval and the overall storage and processing of data according to Regulation (EU) 2016/ 679 GDPR. After participants gave their explicit consent, they were instructed to interact with the chatbot with the aim of choosing any product (food) it presented. After interacting with the chatbot and having accomplished the task, participants answered the questions regarding perceptions about their experience with the chatbot. The questionnaire consisted of a first part designed to acquire demographic insights into the use of messaging apps, chatbots and online purchases experience and a second part consisting of statements regarding the constructs.

A total of 193 millennials took part in this study, which corresponds to about 48 subjects per group aged $22-34$ years $(M=22.6, \mathrm{SD}=1.8)$. As expected, most of the respondents reported the daily use of messaging apps, as out of all respondents, only $3.6 \%$ indicated they had no - or very little - use of messaging apps. The survey recorded the online purchasing behaviour of the respondents. Only $3.2 \%$ of them indicated they had never made online purchases, while $86.5 \%$ declared they made online purchases between one and four times per month. After the interaction with the chatbot, participants were asked if they had ever used such a technology in general and for online purchases. Overall, $79 \%$ had never used it at all and $93 \%$ had never used it for online purchasing.

\section{Stimuli}

Following Chattaraman et al. (2019) and Van Dolen et al. (2007), the social-oriented interaction style chatbot was set up to adopt an informal language. In addition to providing functional guides and information, social-oriented interaction style chatbots maintain an informal conversation through small talk, exclamatory feedback and visual kinesic paralanguage in the form of animated images (GIFs) and emoticons (Luangrath et al., 2017). The task-oriented interaction style chatbot is limited for providing formal guides to help users perform the task, and no social features, with neither GIFs nor emoticons, were set up.

Before the main experiment, a pre-test was carried out to ensure that the manipulation was effective according to Chattaraman et al. (2019). We randomly assigned 78 students (38 men and 40 females, $M_{\text {age }}=20.3 ; S D_{\text {age }}=1.1$ ) to one of the two conditions. The extent to which the interaction with the chatbot was perceived as social-oriented or task-oriented was measured by asking participants how much they thought the chatbot was expressive, enthusiastic, entertaining and friendly on a seven-item Likert scale (1 = "strongly disagree"; 7 = "strongly 
agree"). The responses were averaged to create a single index. As expected, findings revealed that the chatbot was perceived to have a significantly more engaging personality $(\mathrm{t}(51)=6.31, p<0.001)$ when the interaction style was social-oriented $(M=6.00$, $S D=0.91)$ than task-oriented $(M=4.11, S D=0.92)$.

\section{Measures}

Previous research was reviewed to ensure that a comprehensive list of measures was included. The present study adopted validated scales for all dependent variables, with minor changes in wording. For all the measures, responses were recorded on a seven-point Likert scale ( 1 = "strongly disagree"; 7 = "strongly agree"). The measures for social presence were taken from Gefen and Straub (2003) (five items, $M=3.73 ; S D=1.50$ ), and trust was measured accordingly to Pengnate and Sarathy (2017) (four items, $M=5.00 ; S D=1.26$ ), while the measures for perceived enjoyment were adapted from Van der Heijden (2004) (four items, $M=3.75 ; S D=1.48$ ). The attitude towards the chatbot scale (four items, $M=4.49 ; S D=1.59$ ) was adapted from Moon and Kim (2001).

Two control variables were considered in the study: need for affect (NFA), which is an individual difference reflecting variation in the motivation to approach or avoid emotioninducing situations (Appel et al., 2012) and previous chatbot interaction experience. The former was measured with ten items according to Appel et al. (2012) $(M=4.37 ; S D=0.70)$ and was added to control for a psychological dimension that might affect participants' interpersonal relationship perspective. The latter was assessed by asking participants if they had ever interacted with a chatbot before participating in this study; it was categorised using a dichotomous variable (either "Yes" = 1; or "No" = 2).

\section{Results}

First of all, we performed a series of confound checks to control for the possibility that differences in NFA and previous chatbot interaction experience could have been equally distributed among the four conditions. A one-way ANOVA revealed no significant differences in terms of NFA across the four conditions $F(1,191)=0.001, p=0.980$; while a chi-squared analysis revealed that previous chatbot interaction experience had no significant relationship with respect to the interaction style $\left(\chi^{2}(1,187)=0.476, p=0.490\right)$ and avatar conditions $\left.\chi^{2}(1,187)=0.576, p=0.448\right)$.

\section{ANOVA results for social presence}

To test for the effects of interaction style and avatar on social presence, we performed 2 (interaction style: social-oriented or task-oriented) $\times 2$ (avatar: present or absent) betweenparticipants ANOVAs. As regards social presence, the ANOVA revealed a significant main effect of interaction style $(F(1,193)=29.63, p<0.01$, partial $\eta 2=0.14)$, indicating that participants reported a higher level of social presence in the social-oriented interaction style $(M=4.29 ; S D=1.42)$ than in the task-oriented interaction style condition $(M=3.19$; $S D=1.39$ ). The presence of the avatar, however, had an insignificant effect on social presence $(F(1,193)=0.01, p=0.91)$. Even taking into account a different affective involvement when using the chatbot - that is including NFA as a covariate - the relation between interaction style and social presence revealed a significant positive effect $(F(1,191)=29.733, p<0.000$, partial $\eta 2=0.14)$, while avatar presence was still found to be not significant $(F(1$, $191)=0.040, p=0.841$ ). When controlling for previous chatbot interaction experience, social presence was still significantly influenced by interaction style $(F(1,186)=25.930, p<0.000$, partial $\eta 2=0.14)$ but not by avatar presence $(F(1,186)=0.084, p=0.772)$. The results supported $\mathrm{H} 1$ but did not support H2.
Millennials' attitude toward chatbots 
IJRDM 48,11

1222
PLS analysis

Measurement model. The partial least square structural equation modeling (PLS-SEM) was applied to analyse the proposed research model because such an approach has higher statistical power - which is especially useful for exploratory research - and it better predicts key driver constructs (Aw, 2019). To check the reliability and validity of the constructs, we performed internal consistency, convergent validity and discriminant validity (Hair et al., 2011). We assessed the above validities by analysing Cronbach's alpha ( $\alpha$ ), factor loadings, composite reliability (CR) and average variance extracted (AVE). Cronbach's alpha shows internal consistency reliability as all the values are far above 0.60 (Hair et al., 2011). The findings of the confirmatory factor analysis (CFA) confirmed that all factor loadings are above minimum level 0.7, thus supporting internal consistency (Hair et al., 2011). The value of $\mathrm{CR}$ of all constructs is above 0.8 , while the value of AVE of all constructs is above 0.5. The outcomes show a reasonable convergent validity (Table 1 ).

To assess discriminant validity, Fornell and Larcker (1981) criterion - latent variable correlations and cross loading were considered. As shown in Table 2, the square root of the AVE is higher than the correlation between variables, supporting discriminant validity (Hair et al., 2011). Table 3 highlights that the items' loadings in the main factor are higher than loadings in any other factor.

Structural model. Before analysing the path coefficient, multicollinearity was assessed. The analysis showed that there were no issues as the maximum VIF value (3.8) was below the threshold of 5.0 (Hair et al., 2011). In order to evaluate our hypotheses, we examined the estimated path coefficients of the structural model. Figure 2 shows the results of the model. As previously shown by the ANOVA, interaction style has a significant influence on social presence $(\beta=0.367, S E=0.061, t$-value $=5.994, p<0.001)$, while avatars have an insignificant effect $(\beta=0.007, S E=0.067, t$-value $=0.097, p=0.461)$. The positive relationship between social presence and trust is supported (with $\beta=0.485, S E=0.063, t$ value $=7.728 p<0.001$ )and the same occurs with social presence and perceived enjoyment $(\beta=0.735, S E=0.037, t$-value $=20.055 p<0.001)$; thus. both $\mathrm{H} 3$ and $\mathrm{H} 4$ are supported. Likewise, attitude is positively predicted by trust towards the chatbot $(\beta=0.424, S E=0.063$, $t$-value $=6.692 p<0.001)$ and perceived enjoyment $(\beta=0.440, S E=0.061, t$-value $=7.157$

$p<0.001$ ), confirming H5 and H6. The results of the PLS-SEM analysis do not change when

\begin{tabular}{|c|c|c|c|c|c|c|}
\hline & Construct & Item & Item loading & AVE & Composite reliability & Cronbach's alpha \\
\hline & Social presence & SP1 & 0.837 & 0.754 & 0.939 & 0.918 \\
\hline & & SP2 & 0.862 & & & \\
\hline & & SP3 & 0.849 & & & \\
\hline & & SP4 & 0.896 & & & \\
\hline & & SP5 & 0.895 & & & \\
\hline & Perceived enjoyment & PE1 & 0.898 & 0.746 & 0.921 & 0.886 \\
\hline & & PE2 & 0.813 & & & \\
\hline & & PE3 & 0.884 & & & \\
\hline & & PE4 & 0.857 & & & \\
\hline & Trust & $\mathrm{T} 1$ & 0.897 & 0.725 & 0.913 & 0.872 \\
\hline & & $\mathrm{T} 2$ & 0.818 & & & \\
\hline & & T3 & 0.887 & & & \\
\hline & & $\mathrm{T} 4$ & 0.799 & & & \\
\hline & Attitude towards the chatbot & ATT1 & 0.759 & 0.701 & 0.903 & 0.856 \\
\hline Table 1. & & ATT2 & 0.910 & & & \\
\hline Reliability analysis and & & ATT3 & 0.871 & & & \\
\hline convergent validity & & ATT4 & 0.800 & & & \\
\hline
\end{tabular}

Table 1.

Reliability analysis and convergent validity 
controlling for both NFA and previous chatbot interaction experience. The coefficient of determination value $\left(R^{2}\right)$ for attitude towards the chatbot is 0.562 , which represents a good value for behavioural research (Hair et al., 2017). The coefficients of paths and determination values are displayed in Figure 2.

Millennials' attitude toward chatbots

\begin{tabular}{|c|c|c|c|c|c|}
\hline Construct & $\begin{array}{c}\text { Social } \\
\text { presence }\end{array}$ & $\begin{array}{l}\text { Perceived } \\
\text { enjoyment }\end{array}$ & Trust & $\begin{array}{l}\text { Attitude towards the } \\
\text { chatbot }\end{array}$ & \\
\hline Social presence & 0.868 & - & - & - & \\
\hline Perceived enjoyment & 0.735 & 0.864 & - & - & \\
\hline Trust & 0.485 & 0.507 & 0.851 & - & \\
\hline $\begin{array}{l}\text { Attitude towards the } \\
\text { chatbot }\end{array}$ & 0.578 & 0.655 & 0.647 & 0.837 & $\begin{array}{r}\text { Discriminant validity - } \\
\text { latent variable }\end{array}$ \\
\hline \multicolumn{5}{|c|}{$\begin{array}{l}\text { Note(s): The italic values in diagonals represent the square root of AVE and the off diagonals represent the } \\
\text { correlations }\end{array}$} & $\begin{array}{r}\text { correlations and square } \\
\text { root of AVE }\end{array}$ \\
\hline
\end{tabular}

\begin{tabular}{lcccc}
\hline Construct & Social presence & Perceived enjoyment & Trust & Attitude towards the chatbot \\
\hline SP1 & 0.837 & 0.656 & 0.486 & 0.542 \\
SP2 & 0.862 & 0.576 & 0.398 & 0.483 \\
SP3 & 0.849 & 0.671 & 0.446 & 0.519 \\
SP4 & 0.896 & 0.643 & 0.358 & 0.449 \\
SP5 & 0.895 & 0.630 & 0.401 & 0.506 \\
PE1 & 0.670 & 0.898 & 0.417 & 0.578 \\
PE2 & 0.641 & 0.812 & 0.404 & 0.537 \\
PE3 & 0.612 & 0.884 & 0.508 & 0.617 \\
PE4 & 0.613 & 0.858 & 0.418 & 0.526 \\
T1 & 0.408 & 0.430 & 0.899 & 0.519 \\
T2 & 0.464 & 0.438 & 0.816 & 0.549 \\
T3 & 0.391 & 0.387 & 0.889 & 0.590 \\
T4 & 0.385 & 0.472 & 0.797 & 0.539 \\
ATT1 & 0.322 & 0.353 & 0.592 & 0.759 \\
ATT2 & 0.575 & 0.638 & 0.625 & 0.910 \\
ATT3 & 0.308 & 0.328 & 0.619 & 0.871 \\
ATT4 & 0.543 & 0.588 & 0.517 & 0.800
\end{tabular}

Note(s): Italic values are loadings for each item, which are above the recommended value of 0.5 ; and an item's loadings on its own variable are higher than all of its cross loadings with other variable

Table 3.

Cross loading (discriminant validity)

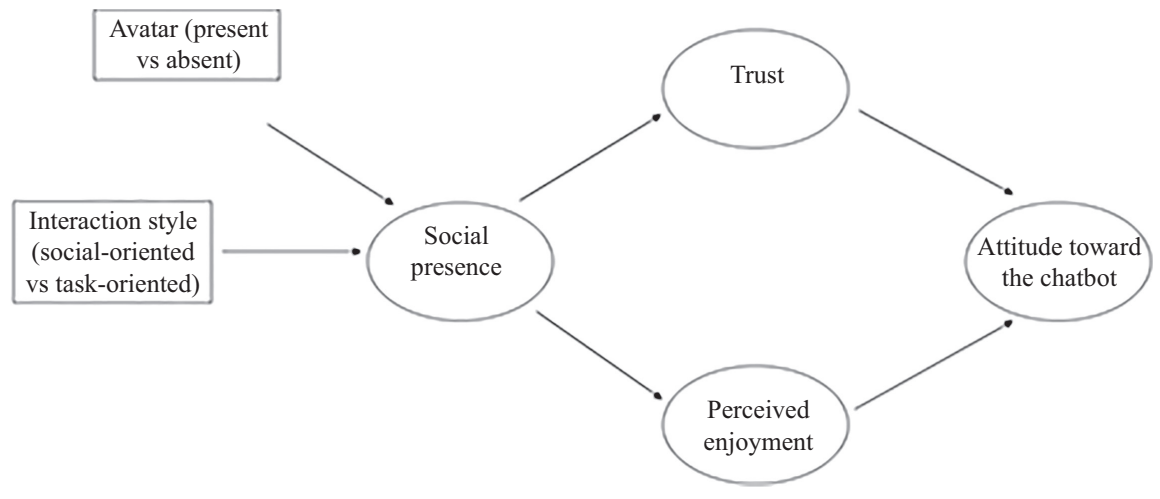

Figure 1.

Depicts the research model 


\section{IJRDM 48,11}

1224

Figure 2.

Structural relationships and hypotheses testing

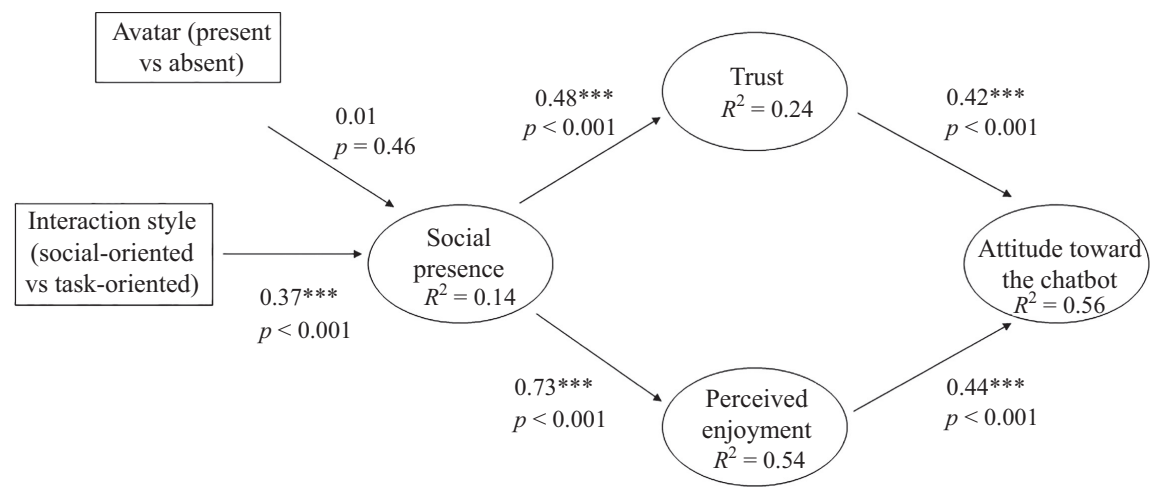

We used the blindfolding procedure to evaluate the relevance of exogenous variables to model performance. This technique examines each construct predictive relevance by computing changes in the criterion estimates $\left(Q^{2}\right)$ (Hair et al., 2017). Our results of StoneGeisser's blindfolding technique $\left(Q^{2}\right)$ show that social presence $\left(Q^{2}=0.093\right)$, consumers' trust in the chatbot $\left(Q^{2}=0.172\right)$, perceived enjoyment $\left(Q^{2}=0.379\right)$ and attitude $\left(Q^{2}=0.364\right)$ have satisfactory predictive relevance since their values are far above 0 (Thakur, 2018).

In order to advance the understanding of the relationship between the variables, we tested the mediating effects with 5,000 bootstrapping resamples to highlight the direct and indirect effects of interaction style on attitude towards the chatbot through social presence, perceived enjoyment and trust (Table 4). Table 4 also shows the significant indirect effects of social presence on attitude towards the chatbot through both mediators. The indirect effect via perceived enjoyment $(\beta=0.392, p<0.001,95 \%$ C.I. $[0.258,0.516])$ is slightly higher than trust towards the chatbot $(\beta=0.189, p<0.001,95 \%$ C.I. [0.113, 0.294]).

Overall, because the direct effect of interaction style on attitude was not statistically significant $(\beta=-0.073, p=0.1295 \%$ C.I. [-0.160, 0.026]), we conclude that social presence, perceived enjoyment and trust fully mediate the effects of interaction style on attitude towards the chatbot (Hair et al., 2017).

\section{Discussion and implications}

\section{Discussion}

AI offers additional opportunities for conversational commerce, which refers to transactions started and completed through chat interfaces such as chatbots (Tuzovic and Paluch, 2018). This is particularly true for millennials, since chatbots represent a suitable tool for meeting

\begin{tabular}{lccc}
\hline Mediation path & Indirect effect with bootstrap estimate (b) & Lower 95\% BCBCI & Upper 95\% BCBCI \\
\hline $\mathrm{IS} \rightarrow \mathrm{SP} \rightarrow \mathrm{PE} \rightarrow \mathrm{A}$ & $0.151^{* * * *}$ & 0.085 & 0.230 \\
$\mathrm{IS} \rightarrow \mathrm{SP} \rightarrow \mathrm{T} \rightarrow \mathrm{A}$ & $0.073^{* * *}$ & 0.040 & 0.120 \\
$\mathrm{IS} \rightarrow \mathrm{SP} \rightarrow \mathrm{PE}$ & $0.286^{* * *}$ & 0.187 & 0.388 \\
$\mathrm{IS} \rightarrow \mathrm{SP} \rightarrow \mathrm{T}$ & $0.187^{* * *}$ & 0.117 & 0.269 \\
$\mathrm{SP} \rightarrow \mathrm{PE} \rightarrow \mathrm{A}$ & $0.392^{* * *}$ & 0.258 & 0.516 \\
$\mathrm{SP} \rightarrow \mathrm{T} \rightarrow \mathrm{A}$ & $0.189^{* * *}$ & 0.113 & 0.294
\end{tabular}

Table 4.

$\mathrm{SP} \rightarrow \mathrm{T} \rightarrow \mathrm{A}$

$0.189^{* * * *}$

0.113

0.294

Note(s): NFA and past experience with chatbots were considered as control variables. Bias corrected and accelerated $(\mathrm{BCa})$ bootstrap confidence intervals were based on 5,000 samples. ***p $<0.001$ 
their online interaction preferences. Given these premises, it comes as no surprise that online companies have started to feel the need to understand what contributes to building and enhancing younger consumers' engagement within these platforms (Araujo, 2018). Despite millennials' predominant use of instant text messaging suggesting that they are more likely to give chatbots a chance, little is still known about the factors that positively influence their attitude towards this technology. In order to shed light on this matter, our study builds upon prior research on consumers' attitude and response to online conversational agents applied for retailing purposes, a research area, that, to date, is still limited (Zarouali et al., 2018).

As a matter of fact, compared to offline shopping, the online purchasing experience may be viewed as lacking human warmth and sociability as it is more impersonal, anonymous and automated. For these reasons, understanding how to create a higher level of engagement in online environments with new technologies such as chatbots is a complex process (Cyr et al., 2007). Our results align with prior studies on social presence research in the online domain and further confirms previous findings assessing that social presence is a factor at the heart of consumer experience with online services (Hassanein and Head, 2005; Cyr et al., 2007; Shen, 2012).

This study contributes to our understanding of the effects of conversational cues on social presence. The results suggest that a social-oriented conversation enhances the feeling that the interactant is a social entity (i.e. social presence). Compared to Araujo's (2018) study, where the presence of anthropomorphic cues (in terms of human name and greetings) were not enough to establish a significant level of social presence, our study suggests that socioemotional, affective and relational aspects need to be present in the interaction in order to enhance perception of social presence. The current study complements Chattaraman et al. (2019), who proved the effectiveness of social interaction style on older users' trust and perceived interactivity when the interaction style matches the task-competency of the older user. From this perspective, this study extends social-oriented interaction style positive outcomes (compared to a task-oriented interaction style) in terms of social presence to a specific and marketing appealing younger audience.

The present work also suggests a key finding regarding the elements that do (or do not) enhance social presence in a human-chatbot interaction. In contrast to past studies on agents applied on different platforms, where the presence of an avatar was found to enhance the user's perception of social presence of the medium (Gefen and Straub, 2003), the current research cannot support this statement. This result, although conflicting with previous research on the topic, could reasonably be ascribed to the role of the hosting platform. In fact, unlike the placement on websites of avatars and virtual assistant characters that are highly visible thanks to their dominant position on the screen, for app-based chats like Messenger, the visual aspect of the profile image plays only a minimal role with respect to the conversation flow itself. The section for the personal image is very small and located in a rather marginal position with respect to the text.

The second part of the study confirms the role of trust and perceived enjoyment as consequences of social presence and as antecedents of attitude towards the chatbot. In line with past studies, social presence predicts users' joy (Cyr et al., 2007; Hassanein et al., 2009) as well as perceptions of honesty (Gefen and Straub, 2003; Etemad-Sajadi, 2016). At the same time, perceived enjoyment and trust towards the chatbot significantly predict a positive attitude towards the chatbot (Wu and Liu, 2007; Hassanein and Head, 2005).

\section{Theoretical implications}

The conclusions of the research present the following theoretical enlightenment. First, this study enriches the literature on innovative marketing channels through an analysis of the variables that play a major role in human-chatbot interaction for business purposes. In line with the HCI literature, where social presence, perceived enjoyment and trust were found to
Millennials' attitude toward chatbots

1225 
IJRDM

48,11

have great value for online technologies (e.g. website, Hassanein, and Head, 2005), such constructs can be considered as a proxy of the overall user experience with chatbots.

The present study further contributes to the literature on the social presence theory and chatbot relationship by demonstrating that a chatbot showing psychological closeness that employs a warm and friendly conversation can be a fundamental trigger for generating a better experience of social presence (Cyr et al., 2007). Specifically, this work draws attention to the necessity of considering interaction style in human-chatbot interactions as an antecedent of social presence, indicating that a social-oriented interaction style may work to compensate for the impersonal nature often associated with AI .

The mediation analysis, which is at the heart of both the advancement of social presence theory and the refinement of chatbots guiding users in the purchasing process, allowed us to identify psychological mediators able to capitalise upon key processes involved in generating positive outcomes. In this regard, the study sheds light on two important effects of social presence in chatbots applied for online retailing, i.e. trust and enjoyment. Both perceived enjoyment and trust towards the chatbot were found to have a significant positive influence on the overall attitude towards the chatbot. So, drawing from the results of the mediating effect, on the one hand, this work extends knowledge on hedonic motivation which leads to positive attitudes in the online shopping environment (Koufaris, 2002). On the other hand, our results advance research on online trust (Wu and Liu, 2007) confirming that trust plays a central role for the overall perception of chatbots applied for business purposes.

\section{Practical implications}

The launch and the development of an appropriate chatbot involve a high degree of uncertainty for companies, since they can be programmed in many ways with distinct sets of rules (Zarouali et al., 2018). The present research offers practical support for designing visual and conversational elements of chatbots that enhance their effectiveness for younger segments of the customer base. Specifically, this study encourages retailers to focus on features that enhance a sense of social interaction through a conversational style rather than profile visual cues (i.e. avatars). The study suggests that chatbots applied for retailing purposes need to be fun in order to attract young customers via more enjoyable experiences resulting from social interactions. Companies that wish to make a favourable impression on young consumers should embrace a social relationship perspective and create engaging conversations that include small talk, exclamatory feedback, emoticons and GIFs to increase the level of social presence and consequently perceived enjoyment, trust and attitude towards the chatbots.

\section{Limitations and future research}

This study has some limitations that call for future research. First, participants were asked to complete a fictitious task and only a simulated purchase. While this design aimed to maximise the validity of the study, future research could collect behavioural data from real companies.

The sample is limited to a specific young cohort, which may limit the generalisability of the findings. The future study may overcome this issue and further investigate whether the gender of the chatbot itself influences participants' perceptions (Skjuve et al., 2019). In order to see if the attitude towards the chatbot varies across different levels of involvement and spending, it would be of interest to examine potential moderators such as the type of product (e.g. luxury goods) involved in the operation. Lastly, in view of different online shopping rates across multiple markets, we believe it might be interesting to compare chatbots for conversational commerce among countries with different online shopping rates in order to see if this technology can increment online purchases in countries where such rates are still low. 


\section{References}

Ajzen, I. and Fishbein, M. (1977), "Attitude-behaviour relations: a theoretical analysis and review of empirical research”, Psychological Bulletin, Vol. 84 No. 5, p. 888.

Alnawas, I. and Hemsley-Brown, J. (2018), "The differential effect of cognitive and emotional elements of experience quality on the customer-service provider's relationship", International Journal of Retail and Distribution Management, Vol. 46 No. 2, pp. 125-147.

Appel, M., Gnambs, T. and Maio, G.R. (2012), "A short measure of the need for affect”, Journal of Personality Assessment, Vol. 94 No. 4, pp. 418-426.

Araujo, T. (2018), "Living up to the chatbot hype: the influence of anthropomorphic design cues and communicative agency framing on conversational agent and company perceptions", Computers in Human Behavior, Vol. 85, pp. 183-189.

Aw, E.C.X. (2019), “Understanding the webrooming phenomenon”, International Journal of Retail and Distribution Management, Vol. 47 No. 10, pp. 1074-1092.

Biocca, F., Harms, C. and Burgoon, J.K. (2003), "Toward a more robust theory and measure of social presence: review and suggested criteria", Presence: Teleoperators and Virtual Environments, Vol. 12 No. 5, pp. 456-480.

Brandtzaeg, P.B. and Følstad, A. (2017), "Why people use chatbots", In International Conference on Internet Science, Springer, Cham, pp. 377-392.

Business Insider (2019), "The latest market research, trends, and landscape in the growing AI chatbot industry", available at: https://www.businessinsider.com/chatbot-market-stats-trends? IR=T (accessed 17 March 2019).

Chattaraman, V., Kwon, W.S., Gilbert, J.E. and Ross, K. (2019), "Should AI-Based, conversational digital assistants employ social-or task-oriented interaction style? A task-competency and reciprocity perspective for older adults", Computers in Human Behavior, Vol. 90, pp. 315-330.

Chen, L.D. and Tan, J. (2004), "Technology adaptation in e-commerce: key determinants of virtual stores acceptance", European Management Journal, Vol. 22 No. 1, pp. 74-86.

Chen, C.C., Olfman, L. and Harris, A. (2005), "Differential impacts of social presence on the behaviour modeling approach", International Journal of Technology and Human Interaction, Vol. 1 No. 2, pp. 64-84.

Childers, T.L., Carr, C.L., Peck, J. and Carson, S. (2001), "Hedonic and utilitarian motivations for online retail shopping behaviour", Journal of Retailing, Vol. 77 No. 4, pp. 511-535.

Chung, M., Ko, E., Joung, H. and Kim, S.J. (2018), "Chatbot e-service and customer satisfaction regarding luxury brands", Journal of Business Research, doi: 10.1016/j.jbusres.2018.10.004.

Ciechanowski, L., Przegalinska, A., Magnuski, M. and Gloor, P. (2019), "In the shades of the uncanny valley: an experimental study of human-chatbot interaction", Future Generation Computer Systems, Vol. 92, pp. 539-548.

Corti, K. and Gillespie, A. (2016), "Co-constructing intersubjectivity with artificial conversational agents: people are more likely to initiate repairs of misunderstandings with agents represented as human", Computers in Human Behavior, Vol. 58, pp. 431-442.

Cyr, D., Hassanein, K., Head, M. and Ivanov, A. (2007), "The role of social presence in establishing loyalty in e-service environments", Interacting with Computers, Vol. 19 No. 1, pp. 43-56.

Das, G. (2016), “Antecedents and consequences of trust: an e-tail branding perspective”, International Journal of Retail and Distribution Management, Vol. 44 No. 7, pp. 713-730.

Davis, F.D., Bagozzi, R.P. and Warshaw, P.R. (1992), "Extrinsic and intrinsic motivation to use computers in the workplace", Journal of Applied Social Psychology, Vol. 22 No. 14, pp. 1111-1132.

Etemad-Sajadi, R. (2016), "The impact of online real-time interactivity on patronage intention: the use of avatars", Computers in human behaviour, Vol. 61, pp. 227-232.
Millennials'

attitude toward chatbots 
IJRDM 48,11

Forbes (2016), "Millennials' demand for customization, control and immediacy drives new Jawwy mobile service", available at: https:/www.forbes.com/sites/larrymyler/2016/05/05/millennials-demand-forcustomization-control-and-immediacy-drives-new-jawwy-mobile-service/\#49a6fcd23e14 (accessed 6 May 2019).

Fornell, C. and Larcker, D.F. (1981), "Evaluating structural equation models with unobservable variables and measurement error", Journal of Marketing Research, Vol. 18 No. 1, pp. 39-50.

Gefen, D. and Straub, D. (2003), "Managing user trust in B2C e-services", e-service Journal, Vol. 2 No. 2, pp. 7-24.

Gentsch, P. (2019), "Conversational AI: how (chat) bots will reshape the digital experience", in AI in Marketing, Sales and Service, Palgrave Macmillan, Cham, pp. 81-125.

Gnewuch, U., Morana, S., Adam, M.T.P. and Maedche, A. (2018), "Faster is not always better: understanding the effect of dynamic response delays in human-chatbot interaction", In Proceedings of the European Conference on Information Systems (ECIS).

Go, E. and Sundar, S.S. (2019), "Humanizing Chatbots: the effects of visual, identity and conversational cues on humanness perceptions", Computers in Human Behavior, Vol. 97, pp. 304-316.

Ha, S. and Stoel, L. (2009), "Consumer e-shopping acceptance: antecedents in a technology acceptance model”, Journal of Business Research, Vol. 62 No. 5, pp. 565-571.

Hagberg, J., Sundstrom, M. and Egels-Zandén, N. (2016), "The digitalization of retailing: an exploratory framework", International Journal of Retail and Distribution Management, Vol. 44 No. 7, pp. 694-712.

Hair, J.F., Ringle, C.M. and Sarstedt, M. (2011), "PLS-SEM: indeed a silver bullet", Journal of Marketing Theory and Practice, Vol. 19 No. 2, pp. 139-152.

Hair, J.F. Jr, Sarstedt, M., Ringle, C.M. and Gudergan, S.P. (2017), Advanced Issues in Partial Least Squares Structural Equation Modeling, Sage Publications, Thousand Oaks, CA.

Hassanein, K. and Head, M. (2005), "The impact of infusing social presence in the web interface: an investigation across product types", International Journal of Electronic Commerce, Vol. 10 No. 2, pp. 31-55.

Hassanein, K. and Head, M. (2007), "Manipulating perceived social presence through the web interface and its impact on attitude towards online shopping", International Journal of Human-Computer Studies, Vol. 65 No. 8, pp. 689-708.

Hassanein, K., Head, M. and Ju, C. (2009), "A cross-cultural comparison of the impact of social presence on website trust, usefulness and enjoyment", International Journal of Electronic Business, Vol. 7 No. 6 , p. 625 .

Hill, J., Ford, W.R. and Farreras, I.G. (2015), "Real conversations with artificial intelligence: a comparison between human-human online conversations and human-chatbot conversations", Computers in Human Behavior, Vol. 49, pp. 245-250.

Ho, A., Hancock, J. and Miner, A.S. (2018), "Psychological, relational, and emotional effects of self-disclosure after conversations with a chatbot”, Journal of Communication, Vol. 68 No. 4, pp. 712-733.

Jiang, C., Rashid, R.M. and Wang, J. (2019), "Investigating the role of social presence dimensions and information support on consumers' trust and shopping intentions", Journal of Retailing and Consumer Services, Vol. 51, pp. 263-270.

Kim, H., Suh, K.S. and Lee, U.K. (2013), "Effects of collaborative online shopping on shopping experience through social and relational perspectives", Information and Management, Vol. 50 No. 4, pp. 169-180.

Komiak, S.Y. and Benbasat, I. (2006), "The effects of personalization and familiarity on trust and adoption of recommendation agents", MIS Quarterly, Vol. 30 No. 4, pp. 941-960.

Koufaris, M. (2002), "Applying the technology acceptance model and flow theory to online consumer behaviour", Information Systems Research, Vol. 13 No. 2, pp. 205-223. 
Lee, S. and Dubinsky, A. (2003), "Influence of salesperson characteristics and customer emotion on retail dyadic relationships", International Review of Retail Distribution and Consumer Research, Vol. 13 No. 1, pp. 21-36.

Lee, J.N., Pi, S.M., Kwok, R.C.W. and Huynh, M.Q. (2003), "The contribution of commitment value in Internet commerce: an empirical investigation", Journal of the Association for Information Systems, Vol. 4 No. 1, p. 2.

Leidner, R. (1993), Fast Food, Fast Talk: Service Work and the Routinization of Everyday Life, Univ of California Press, Berkeley, CA.

Millennials' attitude toward chatbots

1229

Li, D., Chau, P.Y.K. and Lou, H. (2005), "Understanding individual adoption of instant messaging: an empirical investigation", Journal of the Association for Information Systems, Vol. 6 No. 4, pp. 102-129.

Liu, B. and Sundar, S.S. (2018), "Should machines express sympathy and empathy? Experiments with a health advice chatbot", Cyberpsychology, Behavior, and Social Networking, Vol. 21 No. 10, pp. 625-636.

Lombard, M. and Ditton, T. (1997), "At the heart of it all: the concept of presence", Journal of Computer-Mediated Communication, Vol. 3 No. 2, pp. 1-43.

Lu, B., Fan, W. and Zhou, M. (2016), "Social presence, trust, and social commerce purchase intention: an empirical research", Computers in Human Behavior, Vol. 56, pp. 225-237.

Luangrath, A.W., Peck, J. and Barger, V.A. (2017), "Textual paralanguage and its implications for marketing communications", Journal of Consumer Psychology, Vol. 27 No. 1, pp. 98-107.

Luo, J.T., McGoldrick, P., Beatty, S. and Keeling, K.A. (2006), "On-screen characters: their design and influence on consumer trust", Journal of Services Marketing.

Mayer, R.C., Davis, J.H. and Schoorman, F.D. (1995), “An integrative model of organizational trust”, Academy of Management Review, Vol. 20, pp. 709-734.

McKenna, K.Y.A., Green, A.S. and Gleason, M.E.J. (2002), "Relationship formation on the internet: what's the big attraction?", Journal of Social Issues, Vol. 58 No. 1, pp. 9-31.

Mero, J. (2018), "The effects of two-way communication and chat service usage on consumer attitudes in the e-commerce retailing sector", Electronic Markets, Vol. 28 No. 2, pp. 205-217.

Ming-Chi, L. (2009), "Factors influencing the adoption of internet banking: an integration of TAM and TPB with perceived risk and perceived benefit", Electronic Commerce Research and Applications, Vol. 8 No. 3, pp. 130-141.

Moon, J. and Kim, Y. (2001), "Extending the TAM for a WorldWideWeb context", Information and Management, Vol. 38 No. 4, pp. 217-230.

Moore, M. (2012), "Interactive media usage among millennial consumers", Journal of Consumer Marketing, Vol. 29 No. 6, pp. 436-444.

Nowak, K.L. and Biocca, F. (2003), "The effect of the agency and anthropomorphism on users' sense of telepresence, copresence, and social presence in virtual environments", Presence: Teleoperators and Virtual Environments, Vol. 12 No. 5, pp. 481-494.

Nowak, K.L. and Fox, J. (2018), "Avatars and computer-mediated communication: a review of the definitions, uses, and effects of digital representations", Review of Communication Research, Vol. 6, pp. 30-53.

Oracle (2019), "What is a chatbot?", available at https:/www.oracle.com/solutions/chatbots/what-is-achatbot/ (accessed 8 October 2019).

Pengnate, S.F. and Sarathy, R. (2017), "An experimental investigation of the influence of website emotional design features on trust in unfamiliar online vendors", Computers in Human Behavior, Vol. 67, pp. 49-60.

Qiu, L. and Benbasat, I. (2009), "Evaluating anthropomorphic product recommendation agents: a social relationship perspective to designing information systems", Journal of Management Information Systems, Vol. 25 No. 4, pp. 145-182. 
IJRDM 48,11

Reeves, B. and Nass, C.I. (1996), The Media Equation: How People Treat Computers, Television, and New Media like Real People and Places, Cambridge University Press, Stanford, CA.

Shen, J. (2012), "Social comparison, social presence, and enjoyment in the acceptance of social shopping websites", Journal of Electronic Commerce Research, Vol. 13 No. 3, p. 198.

Siau, K. and Shen, Z. (2003), "Building customer trust in mobile commerce", Communications of the ACM, Vol. 46 No. 4, pp. 91-94.

Skalski, P. and Tamborini, R. (2007), "The role of social presence in interactive agent-based persuasion”, Media Psychology, Vol. 10 No. 3, pp. 385-413.

Skjuve, M., Haugstveit, I.M., Følstad, A. and Brandtzaeg, P.B. (2019), "Help! Is my chatbot falling into the uncanny valley?: an empirical study of user experience in human-chatbot interaction", Human Technology, Vol. 15 No. 1.

Smestad, T.L. and Volden, F. (2018), "Chatbot personalities matters", In International Conference on Internet Science, Springer, Cham, pp. 170-181.

Suh, B. and Han, I. (2002), "Effect of trust on customer acceptance of Internet banking", Electronic Commerce Research and Applications, Vol. 1 Nos 3-4, pp. 247-263.

Suki, N.M. and Suki, N.M. (2007), "Online buying innovativeness: effects of perceived value, perceived risk and perceived enjoyment", International Journal of Business and Society, Vol. 8 No. 2, pp. 81-93.

Thakur, R. (2018), "The role of self-efficacy and customer satisfaction in driving loyalty to the mobile shopping application”, International Journal of Retail and Distribution Management, Vol. 46 No. 3, pp. 283-303.

Toader, D.C., Boca, G., Toader, R., Măcelaru, M., Toader, C., Ighian, D. and Rădulescu, A.T. (2020), "The effect of social presence and chatbot errors on trust", Sustainability, Vol. 12 No. 1, p. 256.

Trivedi, J. (2019), "Examining the customer experience of using banking Chatbots and its impact on brand love: the moderating role of perceived risk", Journal of Internet Commerce, Vol. 18 No. 1, pp. 91-111.

Tuzovic, S. and Paluch, S. (2018), "Conversational commerce-a new era for service business development?", in Service Business Development, Springer Gabler, Wiesbaden, pp. 81-100.

Van der Heijden, H. (2003), "Factors influencing the usage of websites: the case of a generic portal in The Netherlands", Information and Management, Vol. 40 No. 6, pp. 541-549.

Van der Heijden, H. (2004), "User acceptance of hedonic information systems”, MIS Quarterly, Vol. 28 No. 4, pp. 695-704.

Van Dolen, W.M., Dabholkar, P.A. and De Ruyter, K. (2007), "Satisfaction with online commercial group chat: the influence of perceived technology attributes, chat group characteristics, and advisor communication style", Journal of Retailing, Vol. 83 No. 3, pp. 339-358.

Wang, W. and Benbasat, I. (2008), "Attributions of trust in decision support technologies: a study of recommendation agents for e-commerce", Journal of Management Information Systems, Vol. 24 No. 4, pp. 249-273.

Wang, L.C., Baker, J., Wagner, J.A. and Wakefield, K. (2007), “Can a retail web site be social?”, Journal of Marketing, Vol. 71 No. 3, pp. 143-157.

Whang, C. and Im, H. (2018), "Does recommendation matter for trusting beliefs and trusting intentions? Focused on different types of recommender system and sponsored recommendation", International Journal of Retail and Distribution Management, Vol. 46 No. 10 , pp. $944-958$.

Wu, I.-L. and Chen, J.-L. (2005), "An extension of Trust and TAM model with TPB in the initial adoption of on-line tax: an empirical study", International Journal of Human-Computer Studies, Vol. 62 No. 6, pp. 784-808.

Wu, W.Y. and Ke, C.C. (2015), "An online shopping behaviour model integrating personality traits, perceived risk, and technology acceptance", Social Behaviour and Personality: An International Journal, Vol. 43 No. 1, pp. 85-97. 
Wu, J. and Liu, D. (2007), "The effects of trust and enjoyment on intention to play online games", Journal of Electronic Commerce Research, Vol. 8 No. 2, pp. 128-140.

Yu, J., Ha, I., Choi, M. and Rho, J. (2005), "Extending the TAM for a t-commerce", Information and Management, Vol. 42 No. 7, pp. 965-976.

Millennials' attitude toward chatbots

Zarouali, B., Van den Broeck, E., Walrave, M. and Poels, K. (2018), "Predicting consumer responses to a chatbot on Facebook”, Cyberpsychology, Behavior, and Social Networking, Vol. 21 No. 8, pp. 491-497.

\section{Appendix 1}

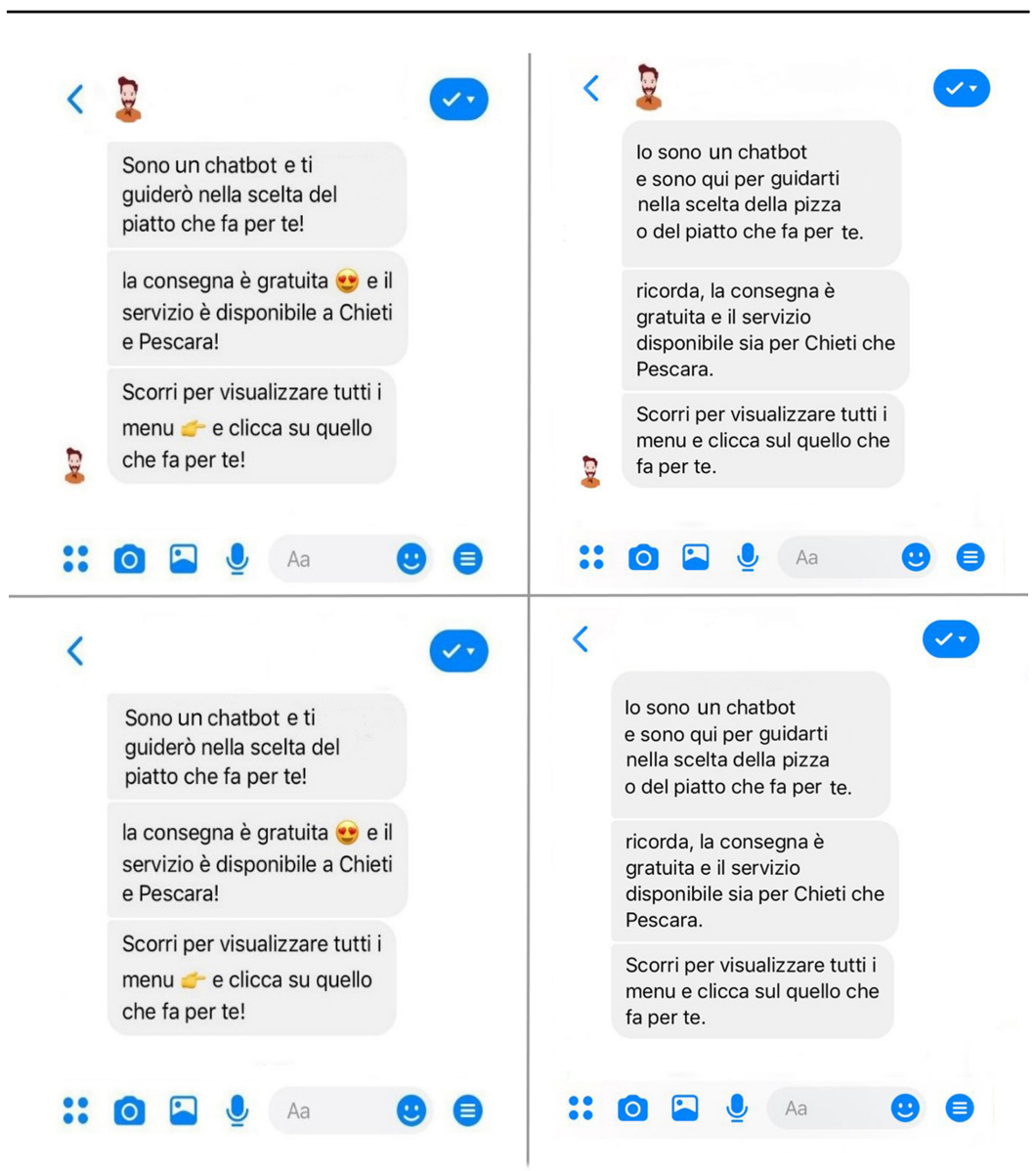

Note(s): Example of social-oriented communication style is on the left, task-oriented comunication style is on the right. The chatbot with avatar is above, the chatbot with no avatar is below.

Figure A1.

Original Italian versions of the four chatbots 
IJRDM 48,11

1232

Figure A2.

Focus on the taskoriented communication style vs social-oriented communication style

\section{Appendix 2}

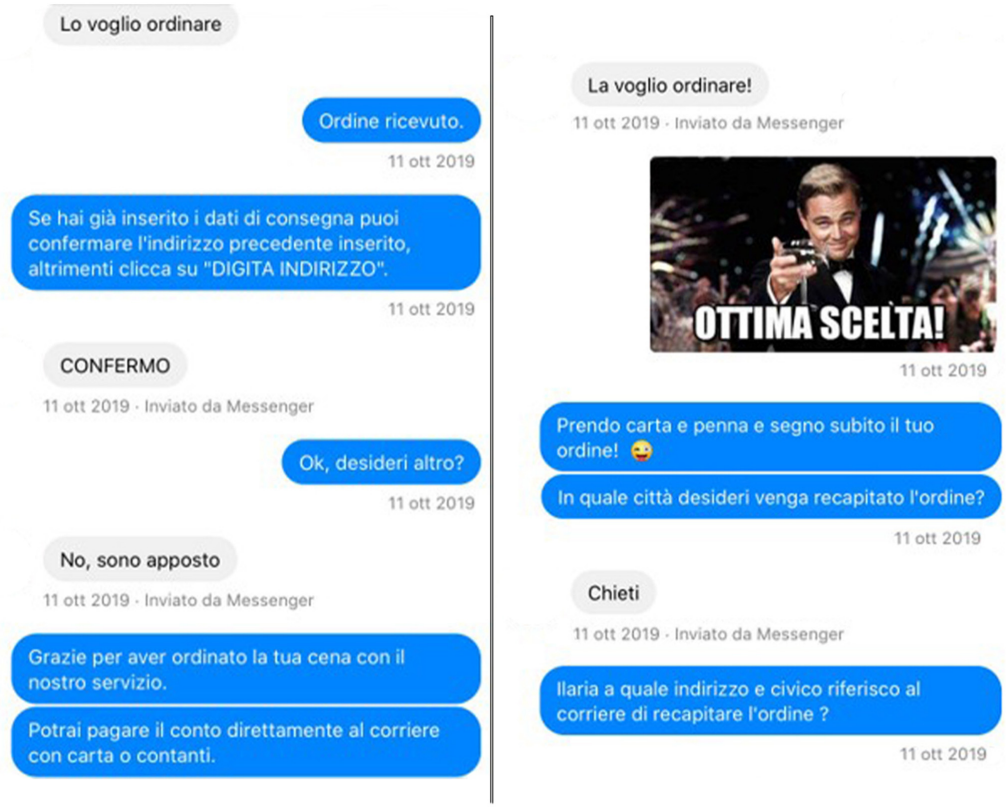

Note(s): Task-oriented interaction style (left) is formal. The chatbot's communication is limited to providing guides and information to help user perform the task, no social elements are presented

Social-oriented communication style (right) is informal. Small talk, jokes, exclamatory feedbacks emoticons and GIFs are applied. In the GIF displayed Leonardo Di Caprio in a scene from the movie "The Great Gatsby" says "Great choice!" as exclamatory feedback 
Appendix 3

English translation of the human-chatbot interactions in Appendix 1-2.

Millennials' attitude toward chatbots

Task-oriented communication style

Social-oriented communication style

Appendix 1 translation

I am a chatbot and I am here to help you to choose the dish

that best suits you

Delivery is free and available in Pescara and Chieti

Swipe to see all the menus and click on the one that is right for you

Appendix 2 translation

I want to order it

Order received

If you have already entered your delivery information, you can confirm the address otherwise click on "enter address"

I confirm the address

Thank you for ordering with our service

You can pay to the courier by card or cash

Im a chatbot and I'm here to help you to

choose the dish that best suits you!

Delivery is free \&1F60D; and available in

Pescara and Chieti!

Swipe to see all the menus \&1F449; and click on the one that's right for you!

I want to order it!

Great choice!

Let me grab paper and pen so I can write down your order \&1F61C;

Where should the order be delivered?

Chieti

Which is the address where you want the order to be delivered?

Corresponding author

Roberta De Cicco can be contacted at: roberta.decicco@unich.it

For instructions on how to order reprints of this article, please visit our website:

www.emeraldgrouppublishing.com/licensing/reprints.htm

Or contact us for further details: permissions@emeraldinsight.com 